doubtedly, the predominant reason for their inclusion in cured meats has been the fact that they occasion a desirable colour in the finished product ${ }^{3}$; but it appears that they may also play an important part in producing a typical "cured" flavour". When consumed directly, quantities of sodium nitrite in excess of $0.2 \mathrm{gm}$. may produce marked toxic effects in man ${ }^{4}$ so that their use in foods must be strictly controlled. For this reason pure food regulations both on the North American continent and in Great Britain forbid the inclusion of more than 0.02 per cent ( 200 parts per million) of sodium nitrite in cured meats.

Very little attention appears to have been paid to the fact that nitrites may, under certain conditions, play an important part in retarding bacterial development on, and thus delay the spoilage of, meats and related products. Lewis and Moran ${ }^{5}$ observed that growth of the mixed bacterial flora of minced beef in experimental brines was retarded by $0.03-1.5$ per cent of sodium nitrite. Their work, as well as that of Tanner and Evans ${ }^{6}$, indicates that the growth of strict anærobic bacteria of the genus Clostridium is inhibited only by relatively large amounts of nitrite. Other investigators ${ }^{\mathbf{7}, 8}$ have observed that 0.4 per cent of sodium nitrite inhibits the growth of certain facultative anærobes. Thus most of the available literature has indicated that it is only rather large concentrations of nitrite, usually greatly in excess of the 0.02 per cent permitted by law, which will hinder or prevent bacterial development.

About two years ago experiments were carried out at this Station in which it was shown that bacterial spoilage of fish flesh is strongly delayed by incorporation of small amounts of nitrite salts?. The reason for this was sought, and it was found that bacteria are only susceptible to low concentrations of nitrites at $p H$ values below $7 \cdot 0$, and that the muscle of fish shortly after capture becomes sufficiently acid (for example, $p \mathrm{H} 6$ to $6 \cdot 6$ ) for these salts to exert their bacteriostatic action ${ }^{10}$. Not all bacteria studied have proved equally susceptible to nitrite, and certain organisms do not appear to be inhibited. However, growth of species of the following bacterial genera at $p H 5 \cdot 7$ or $6 \cdot 0$ has either been markedly inhibited, or in certain instances entirely prevented, by 0.02 per cent of sodium nitrite: Achromobacter, Flavobacterium, Pseudomonas, Micrococcus, Escherichia and Aerobacter (also one species of Torula) ${ }^{11}$.

Attempts have been made to determine by what mechanism nitrites exert their inhibitory action. The possibility that they act by combining with respiratory hæmatin compounds suggested itself, especially in view of the fact that Ingram $^{12}$ has found that oxygen uptake in the case of the aerobic, cytochrome-containing organism, Bacillus cereus, is very strongly inhibited by traces of nitrite. However, it has been found that there is no apparent relationship between inhibition of growth by nitrite and its effect on respiration. Thus in certain instances growth of a given organism was strongly or completely inhibited at $p \mathrm{H} 6 \cdot 0$ by 0.02 per cent sodium nitrite, whereas under similar conditions its aerobic respiration was not significantly inhibited ${ }^{11}$. The possibility that salts of this type inactivate certain enzymes by combining with their amino groups as was originally suggested by Quastel and Wooldridge ${ }^{18}$ must not be overlooked. Since it has recently been shown that certain organisms remain viable after exposure to 38.8 per cent sodium nitrite at $p \mathrm{H}$. 3-8 for ten minutes ${ }^{14}$, it would appear rather unlikely that nitrites are able to act in a bactericidal capacity. H. L. A. TARR.

Pacific Fisheries Experimental Station, Prince Rupert, B. C. Feb. 10.

1 Kerr, Marsh, Schroeder and Boyer, $J$. Agric. Res., 33, 541 (1926). - Brooks, Haines, Moran and Pace, Food Inv. Bd. Gt. Brit., Spec. Rep. No, 49 (1940).

3rooks, Proc. Roy. Soc., B, 123, 368 (1937).

- Reiss, Meyer and Müller, Z. Untersuch. Lebensmittel, 55, 325 (1928).

$\checkmark$ Lewis and Moran, Inst. Amer. Meat Packers, Bull. No. 4 (1928),

- Tanner and Evans, Zbl. Bakt., Abt. II, 91, 1 (1934).

"Stephenson, "Bacterial Metabolism", London (1939).

'Landerkin, Food Res., 5, 205 (1940).

- Tarr and Sunderland, Fish. Res. Bd. Can., Prog. Rep. Paciffc, 39, 13 (1939) ; 40, 14 (1939); J. Fish. Res. Bd. Canada, 5, $148(1940)$

1o Tarr and Sunderland, Fish. Res. Bd. Can., Prog. Rep. Paciflc, 44, 16 (1940).

${ }^{11}$ Tarr, J. Fish. Res. Bd. Canada (in press).

12 Ingram, J. Bact., 33, 613 (1939).

${ }^{13}$ Quastel and Woolridge, Biochem. J., 21, 148 (1927).

"3ittenbender, Degering, Tetrault, Feasley and Gwynn, Ind. Eng. Chem., 32, 996 (1940).

\section{$\beta$-Glucosaminase in Testes}

Diffusing factor preparations from various sources cause a rapid decrease in the viscosity of certain mucins (for example, hyaluronic acid) and if contact is maintained for a longer period hydrolysis of the polysaccharide can be detected by an increase in the reducing power of the mixture ${ }^{1}$. Since the mucins in question are believed to be built up of $\mathrm{N}$-acetylglucosamine and uronic acid residues it seemed likely that an enzyme capable of hydrolysing them would also hydrolyse other $\mathrm{N}$-acetylglucosaminides. It has, in fact, been demonstrated (see accompanying table) that a concentrate of testicular diffusing factor ${ }^{2}$ will hydrolyse $\mathrm{N}$-acetyl- $\beta$-phenylglucosaminide much more readily than any other glycoside examined.

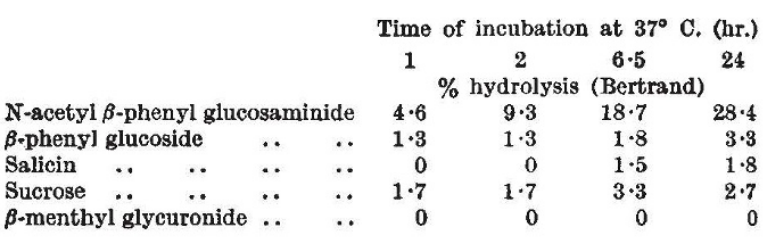

The optimum $p \mathrm{H}$ for this $\beta$-glucosaminase $(4 \cdot 8)$ is close to that at which diffusing factor preparations exert their maximum effect on the viscosity of hyaluronic acid ${ }^{3}$. There are, however, certain facts which suggest that the two effects-decrease in viscosity and increase in reducing power-may not necessarily be due to the same enzyme. When mucins of the hyaluronic acid type are treated with $M / 5 \mathrm{HCl}$ or $M / 5 \mathrm{NaOH}$ at $25^{\circ} \mathrm{C}$. a gradual and irreversible decrease in viscosity occurs. Glycosidic linkages are, as a rule, stable to alkali under these conditions, and it may well be that the viscous material contains linkages of some other type. Moreover, crude emulsin preparations which show $\beta$-glucosaminase activity do not affect the viscosity of hyaluronic acid.

A more detailed account of the $\beta$-glucosaminase activity of testicular extracts and its bearing on the problem of diffusing factors will be published elsewhere.

Chemistry Department,

University of Manchester. March 20.

Marjorie E. East.

J. Madinaveitia.

A. R. TODD.

${ }^{1}$ Chain and Duthie, Nature, 144, 977 (1939).

${ }^{2}$ Madinaveitia, Biochem. J., 32, 1806 (1938); 33, 347 (1939).

${ }^{3}$ Madinaveitia and Quibell, Biochem. J. 34, 625 (1940). 